\title{
The Degree of Practicing Social Values among the Hashemite University B.A. Students in Light of the Current Global Changes
}

\author{
Zohair H. Al-Zoubi ${ }^{1}$ \\ ${ }^{1}$ Faculty of Educational Science, Hashemite University, Zarqa, Jordan \\ Correspondence: Zohair H. Al-Zoubi, Faculty of Educational Science, Hashemite University, Zarqa, Jordan. \\ E-mail: alzubey_1973@yahoo.com
}

Received: November 19, 2013

Accepted: January 8, 2014 Online Published: February 24, 2014

doi:10.5539/res.v6n1p160

URL: http://dx.doi.org/10.5539/res.v6n1p160

\begin{abstract}
This study aimed at identifying the degree of practicing the social values among the B.A. degree students at the Hashemite University in light of the current global changes. It also aimed at identifying the impact of the variables of: gender, the student's studying level, and place of living on the degree of practice of social values among those students.

The community of the study included the B.A. degree students at the Hashemite University during the 2nd semester of the year 2008/2009, with a total of (16472) male and female students. A random layered sample was chosen with a total of (950) male and female students, forming nearly a percentage of $(6 \%)$ from the study community. After calculating the means and standard deviations for the students' answers on the study tool items, and after using One-Way ANOVA and (L.S.D) test, the study came up with the following results:

- $\quad$ the Hashemite University B.A. students' social values degree of practice has had a high level (the entire average was more than 3.5).

- there were statistically significant differences for the practicing degree of social values among the Hashemite University B.A. degree students ascribed to the variable of gender and for the benefit of female students.

- there were statistically significant differences for the practicing degree of social values among the Hashemite University B.A. degree students ascribed to the variable of place of living and for the benefit of rural areas students.

- there were no statistically significant differences for the practicing degree of social values among the Hashemite University B.A. degree students ascribed to the variable of students' studying level.
\end{abstract}

Keywords: values, social values, B.A. degree students, The Hashemite University, the current global changes

\section{Introduction}

Values are considered to be one of the human society features since the human is at the core of values. Also, values are a social process that belongs generally to humankind, deriving their importance and functions from the human's presence in society. Thus, the human society can't exist without values. They are tow firmly connected phenomena, and Krobeir sees it like the paper's tow surfaces in their cohesion. If we remove any human society's values, we would remove out its humanity (Al-Bahi, 1985). Generally, values form a referential frame that controls the individual's and the group's behaviors. Consequently, their role in forming the individual's personality and knowledge is considered the national nature or the national identity (Patrick, 2003).

The issue of values occupies a high-ranking position in our public life, in our speeches and daily behavioral aspects. It also occupies a grand space within the social and cultural studies, especially in religion, art, science, philosophy and others. Besides, the human values are considered the beam that breaks up the human's intellectual darkness, and they have an influence upon his attitudes towards this disordered world which is confused with various intellectual and behavioral events.

Actually, the study of values doesn't stop only inside the range of philosophical thought, but it also goes beyond reaching all life fields, the economical, political and social, that is affecting all aspects of human relations because values are a social necessity. They are also measures and targets that must be found in every organized 
society, either it is developed or developing, because they infiltrate into the individuals forming their attitudes, motives and anticipations. They also appear in the outer conscious and unconscious behavior (Dhiab, 1980).

The concept of values assumes a great importance within the social and psychological sciences since it is one of the factors that unite the individuals' behaviors, and fulfill the unity of thought and behavior within the social life. The role of values within the human being is similar to the role of the captain who administers the ship according to a well-planned intention and target. Thus, understanding the reality of the human being is really the understanding the values which control and guide him. The study of the topic of values attained a great concern from the philosophical thought pioneers as well as the ethical studies experts, both ancient and current (Alayyan \& Aseilah, 2004).

Values are considered one of the human society features. They are a social process that generally characterizes the humankind, deriving its importance and functions from their presence in society. The human society can't exist without values. Generally, values form a referential frame that controls the individual's and the group's behaviors. Consequently, they play a basic role in forming the individual's personality (Patrick, 2003).

The concept of values is one of the common concepts within various human and social sciences, but there is no agreement between scientists on having one definition for this concept because of their different intellectual bases and study fields. According to Parson (1978), values represent the deep commitment the affects the process of selecting and comparing between the available alternatives, and he defined the value as "an item within a mutual symbolic pattern that forms a measure or level of testing among the alternatives available in a certain situation."

Values are important for individuals because they help in forming the individuals and their personalities, identifying their aims and anticipations and the means for achieving that, and also help in creating a preferential measure that represents a referential frame which controls the human behaviors in his public and private life. Consequently, they help in controlling and directing the individuals' behaviors. Honesty is a value, and if it is adopted by the individual, it would direct his behavior against cheating. Also, patience is a value that directs the behavior towards tolerating hardships and resisting weakness. In addition, values represent standard rules as they are measures taken by the individual for evaluating his and others' behaviors, for judging people, deeds, thoughts and situations whether they are positively desirable or negatively undesirable. Also, values help in protecting the individual from doing wrong. Thus, the religious and social values adopted by the individual save him from going astray, so they are preventive factors. They also work as a developing factor for the individual's personality in that they enable him to adapt to the life's stress and difficulties (Ja'neini, 2004).

Values play a great role in solving conflicts and making decisions among individuals considering the system of values as a group of principles that help the individual in making his decisions and solving his conflicts in a way that preserves his rank.

Values are important for the society for their contribution to the society's cohesion and their identification of its goals, ethics and stable principles that guarantee its cohesion for practicing a normal social life. Also, values help in connecting the culture parts with each other so as to appear consistent, serving a certain goal. They also help in directing the thought towards specific ends because any thought whatever it is scientific or advancing, can't progress the nation unless it is linked to the values system. Besides, values play a role in making the right decision, and they also serve as orientations for the individuals and groups behaviors, protecting the society from corruption, and the society can't stand up right without them (Ja'neini, 2004).

Values are explained in the belief that something is very important for a certain individual or a certain group. Since the value is humanitarian and personal depending upon belief, it is necessary to be relative, that is differs among people in view of their needs, desires, conditions and bringing up. Also, it differs from one person to the other, from one generation to the other, from one place to the other, and from one culture to the other. Thus, loving someone or something makes you feel his or its value, and on the other hand, there is no value for what you hate. For example, the value of the professional artist's view of a book on art decorated with pictures is different from a child's view that sees it a source of colorful and beautiful pictures that urge him to cut and play with (Zaqoot, 2000).

\subsection{The Features of Values}

Values have some characteristics that distinguish them for other concepts such as need, reality, belief, attitude or behavior. These features can be summed up as mentioned by (Aqeel \& Abu-Altamen, 2001; Shukri, 2002) as follows:

- $\quad$ they are humanitarian, that is they are concerned with humans not others. 
- $\quad$ they are not connected to a certain time since values are a cognition that is related to past, present and future. Thus, they go far away from the meaning of desires or interests which are connected to the present only.

- $\quad$ they have the quality of contrast because each value has a contrast which means having a positive pole and a negative pole. The positive pole is the one which forms the value, whereas the negative one represents what we can call (the value's reverse or opposite).

- Standardization: which means that values are measures for judging in which they are measured, assessed, explained and illustrated through the human behavior.

- Relativity: which means that they are not ultimate, rather they are relatively stable differing from one society to the other in view of the factors of place, time, culture, geography and ideology.

- $\quad$ they are learnt, i.e. they are acquired through the environment and not inherited. They are taught and acquired through the different social education institutions.

- $\quad$ they are subjective which means that the worth and importance of the value differ from one individual to the other.

\subsection{Values \& Social Changes}

Values play a significant role in the life of individuals, groups and societies to an extent that they become the issue of education due to the fact that education in itself is a value process. Thus, values identify the educational philosophies, goals, and processes, and they control the education institutions and curricula. They are available in every step, every stage, and every educational process. Without values, education becomes chaos. Many researchers see that the signs of confusion in current societies can be ascribed to the absence of commitment to a consistent value system that identifies the individuals behavior and attitudes. That applies to all societies whether developed or developing, western or eastern. Thus, Maslow, one of the American psychologists, described the current age as "the age of standards' absence, the age of emptiness, and a limitless age", where people lack hope and need the existence of what they believe in and sacrifice for (Aqel, 1997).

Within this age which is overcrowded with current global changes, we find ourselves facing big battles, ethical, ideological, economic, political and cultural battles where final results are difficult to be expected because the issue depends upon the opposing side's ability to confront, and then move on from knowledge to modernity and from modernity to what is beyond (Aqeel \& Abu-Altamen, 2001).

The current global changes have made reflections on values, leading to the creation of ethical conflict because of the existence of 2 systems of values which are: the current value system, and the coming values as a result of these changes. These changes clearly appear within the social field. Also, the current global changes have made social effects, some of which are transformations and changes in the social structure which leads to its not following the standards and values which make it through time. But this structure doesn't stay as it is because it gradually develops through the consecutive generations, being affected by interior and exterior effects (Al-Amr, 2001).

Also, those changes have influenced the role of the family in the raising up process, and other new institutions for education have appeared, assuming an effective role, like the space stations, the Internet, the compact disks (CDs) whose transmission is throughout the hour, including behavioral attitudes and values (Shoman, 2001).

The most important social influences made by the current global changes, as stated by (Hijazi, 1999; Abdullah, 1999; Al Amr, 2001) are the following:

- deterioration in the family's role in raising-up for the benefit of modern media and technologies like the space stations, the computer and the Internet.

- $\quad$ the young became the reference for the elderly concerning dealing with the modern technologies such as the computer and the Internet.

- domination of individualism and selfish spirit on the individuals' behaviors where the children's welfare expenses become bigger at the expense of the family's budget.

- deterioration in the average of families' interaction, and the children's tendency towards isolation because they are busy following the space channels' programs, and the Internet......etc.

- deterioration in the father's (family's) authority in controlling the individual's behavior regarding their choices of friends or their commitment to modest dressing, respecting the general taste.

- $\quad$ the measures of friendship have become based on opportunism, hypocrisy and interests. 
- $\quad$ increase in families' complaints of their children's staying up at night.

- faith has transformed into a relative issue controlled by interests and hypocrisy.

- change in our relations with others.

- $\quad$ confusion in the young's religious beliefs, and the deterioration in their religious restraint.

\section{Statement of the Problem}

Values are considered one of the issues around which a big argument has appeared as a result of the recent changes and developments, especially with the progress of globalization that is accompanied by the huge improvements in the field of the recent information, technological and communication revolution. That consequently affected the society's cultural and social structure in general, and the value system in particular. There are some people who believe that values are stable and unable to change, and that they were not affected by the recent changes. Consequently, the values system remained in its local context, witnessing no changes in the values or their standards. On the other hand, there is another opinion indicating that these changes affected the general social system, and consequently affected the young's values system in general.

As a result, it is important to show interest in the young's issues in general and the university youth in particular, as well as showing recognition of their distinguished rank in building the society and their influence upon its components in different fields: social, cultural, economical and political. Also, it is necessary to study the young's troubles, and the values they have as well as their connection to the society's current values system. Hence, it was necessary to conduct this study which embodies the feeling that the young generation is less appreciating, less concerned and less practicing of the social values because of their behaviors and actions. Based on that, the problem of the study is to identify the degree of social values practice among students in light of the current global changes.

\section{The Questions of the Study}

$\mathbf{1}^{\text {st }}$ question: What is the degree of social values practice among the B.A. students at the Hashemite University in light of the current global changes?

$\mathbf{2}^{\text {nd }}$ question: Are there differences in the degree of social values practice among the B.A. students at the Hashemite University in light of the current global changes ascribed to the variables of (gender, students' studying level, place of living)?

\section{The Goals of the Study}

This study aimed at identifying the degree of social values practice among the Hashemite University B.A. degree students. It also aimed at deciding whether there were statistically significant differences in the degree of social values practice among the B.A. degree students at the Hashemite University in light of the current global changes ascribed to the variables of gender, students' studying level, place of living.

\section{Significance of the Study}

This study is important because it:

- $\quad$ Reveals the reality of the social values practiced by the B.A. degree students at the Hashemite University in light of the current global changes, which will give a correct image of the practice degree of the social values practiced by the students, since students are considered the men of tomorrow, the makers of the future and the progress tool. Thus, uncovering the students' values is considered an important and necessary step for understanding the society and its culture, and understanding the positive and negative role those values could play within the process of development.

- $\quad$ Reveals the level of practiced social values among the Hashemite University B.A. degree students in light of the current global changes.

- Helps those concerned with educational issues in identifying the differences in the level of practiced social values among the Hashemite University B.A. degree students in light of the current global changes and according to the variables of gender, students' studying level, place of living.

- Higher education institutions could benefit from the results of this study, that is the educators and the curriculum designers in enhancing and consolidating the universities' programs and curricula so as to suit our Arabic and Islamic culture.

\section{Related Studies}

Al-Hadidi's study (2000) aimed at identifying the extent of students in Jordanian University commitment to the social values prevalent in the Jordanian community. To fulfill this end, the researcher used a scale he developed 
to measure the values within the following fields: self characteristics, handling, rights and duties, family and social education, way of living, and social relations and connections.

The results indicated that the Jordanian universities' students follow the prevailing social values at a high degree for most of the values separately, and for the values together within 3 fields: self characteristics and handling ethics, rights and duties, and social relations and connections. The results also showed statistically significant differences between the students' commitment to values according to the variables of university and gender for the benefit of male students within 4 fields. The sample of the study contained (917) male and female students from 4 universities: University of Jordan, the Hashemite University, Zarqa Private University and Applied Sciences University.

Guan \& Dodder's study (2001) aimed at discussing the relation between the cultural communication and the change in values. This study was conducted to compare between the ethical attitudes of the Chinese students who study in America, and the Chinese students who study in China. The findings of the study indicated that the cultural communication is related to the change in values attitudes among the Chinese students because the students who are culturally communicative show less importance for the cultural values, whereas the students who spent more than 2 years in America are less resistant towards cultural change than those who spent there less than 2 years. Also, the study revealed that the Chinese students in China are more resistant towards the cultural change than the Chinese students of America, particularly among the female students who have got a sense of modesty preservation as a source of protecting their own cultural principles and traditions.

Malhas \& Subhi (2002) conducted a study that aimed at investigating the impact of the variables of: gender, specialization, the university community, nationality, and the family size on the dimensions of the values scale: cognitive, social, scientific, ethical, and cultural for the students of both the University of Jordan and Al-AlBayt University. The results indicated that there is a statistically significant impact for the variable of university community within the dimension of cultural and scientific values, and for the benefit of Malaysian students in both universities. Also, the results indicated that there were statistically significant differences within the cultural, ethical and social values for the benefit of Al-AlBayt University students. In addition, it was revealed that there were also statistically significant differences within the dimension of educational and psychological values for the benefit of Jordan University students, but the study didn't reveal a statistically significant impact for the rest of the variables.

Al-Hneity (2003) conducted a study that aimed at identifying the existence of a conflict between the social values and the organizing values among the Jordanian employees of the government sector, the effect of their personal and functional traits on that, revealing the causes of that conflict and identifying the functional aspects from which employees encounter that conflict greatly. The study came up with the existence of a low degree of conflict between the social values and the organizing values among the governmental sector employees, and that the employees have attitudes that tend to prevail the social values over the organizing values even if that could be against the general interest. The study also showed that the reason of having a conflict between the social values and the organizing values is due to the habits and traditions which oblige them to serve friends and relatives, giving them the priority against others, which means that habits and traditions have got a significant influence in causing the conflict between the values. Besides, the study indicated that being not committed to religion is one of the important causes of value conflict.

Al-Ostath \& Hamdan's study (2004) aimed at evaluating the role of the university in forming the system of values among students, and investigating the relation of that to some variables such as gender, specialization, type of university, level of achievement and the living area. The findings showed that the most insisting values which students lack or want are the following in order: economical values, political, cultural, then the social, followed by the religious values. The results also showed that there were no significant differences in the students' views regarding all roles of university ascribed to gender, except the role of university activities where significant differences were found for the benefit of female students. Regarding the variable of specialization (literary or scientific), the differences were not significant except the views around the role of the university professor where significant differences were found for the benefit of the literary stream. The variable of university type has got significant differences in all roles, and for the benefit of the Islamic University first, and Al-Aqsa University second. The differences were not significant regarding the level of achievement for all roles of the university except the role of the library where significant differences were found and for the benefit of those who got low averages.

Abu-Zaid \& Al-Zyood (2007) conducted a study that aimed at identifying the values that have the most and the least importance among the secondary stage students in Amman as seen by the students themselves, according to 
the variables of gender, class, family income, and the educational directorate. The study came up with the following results: interest in educational values among the secondary stage students was high regarding most of the study tool items and fields in general, and the order of the educational values fields according to its importance among the students was the following: (the domain of political values, then the domain of the religious values, next the domain of the ethical values, splendor values, social values, economical values, then comes the cognitive values). Also, the most important values for those students were (sincerity, boasting with the country's flag, boasting with language, and parents' loyalty), whereas the values which were less important were (developing the manual skills, openness to cultures, self expression and taking care of elderly people). The results also showed that there were no statistically significant differences for interest in educational values among the secondary stage students in Amman ascribed to the variable of gender, and it was indicated that there were statistically significant differences in the interest in educational values among the secondary stage students in Amman ascribed to the variables of class, family income and educational directorate.

\section{Methodology}

\subsection{Population and Sample of the Study}

The population of the study was composed of all B.A. degree students at the Hashemite University, with a total of (20472) male and female students during the $2^{\text {nd }}$ semester of the year 2012/2013. The sample was chosen from the B.A. degree students at the Hashemite University using the deliberate random sample method through identifying the studying years of the students, then choosing the students randomly. The members of the sample were (950) male and female students, representing a percentage of $(5 \%)$ from the study community.

\subsection{Instrument}

The study used a questionnaire as a main tool for accomplishing its aims and answering its questions, and a questionnaire was developed to gather data following the following steps:

- Reviewing the related theoretical literature and the previous studies that are related to the topic of the study.

- $\quad$ Benefiting from these studies for preparing the first version of the questionnaire.

- $\quad$ Referring the first version of the questionnaire to a group of specialized referees in education, psychology and social studies.

- $\quad$ After studying the referees' views, the following points revealed:

- Consensus on the validity of the domains and their suitability to measure what is intended to do.

- Giving some notes around the items regarding the formulation, evaluation, delay, deleting some items, adding new items suggested by most of the arbitrators, since the first version of the questionnaire contained (42) items.

In light of what has been mentioned, proper procedures were taken so as to ensure its logical validity, and the final version of the questionnaire was composed of (38) items, appendix (1).

The study utilized Lickert's fivefold scale where the degree of very strong agreement was given (5) points, the strong agreement degree (4) points, the medium agreement degree (3) points, the little agreement degree (2) points, and the very little agreement degree was given (1) point.

In order to investigate the tool's validity, the questionnaire was reviewed by a group of professors specialized in the college of educational sciences at the Hashemite University, with a total of (14) referees. They were asked to check the suitability of the tool items for the study topic, and to offer any necessary notes. In light of their notes, it was found that some items were low in their connectivity, so they were replaced with new items which were logically valid. Thus, the number of the items in the final version became (38) items.

The tool's stability coefficient was calculated using the Interior Consistency method, the formula of Chronbach Alpha, to ensure the tool's stability. The test stability was $(0.80)$, a significant number that indicates stability and that is also sufficient for the purposes of this study.

\subsection{The Procedures of Correcting the Tool of the Study}

For modifying the study tool and identifying the degree of social values practice among the university students, 3 levels were assigned for the practicing degree. Hence, the average mean which is more than 3.5 was considered of a high level, the average of 2.5-3.49 was considered of a medium level, and the average mean which is less than 2.49 was considered of a low level.

\section{Results and Discussion}

This part of the study addresses the presentation of the results that this study has come up with, and a discussion of these findings. 
$\mathbf{1}^{\text {st }}$ question: What is the degree of social values practice among the B.A. students at the Hashemite University in light of the current global changes?

To find the degree of social values practice, means and standard deviations were calculated for the students' answers on the tool items as shown in table 1 .

Table 1. Social values practicing degree among the students on the tool items

\begin{tabular}{|c|c|c|c|c|c|}
\hline $\begin{array}{l}\text { Item } \\
\text { No. }\end{array}$ & Item & $\begin{array}{l}\text { Item } \\
\text { Rank } \\
\end{array}$ & Mean* & SD & $\begin{array}{c}\text { Degree of } \\
\text { practice }\end{array}$ \\
\hline 1 & I follow modesty when dealing with others. & 14 & 4.09 & 1.12 & High \\
\hline 2 & I seek achieving social integrity inside the society. & 15 & 4.07 & 1.12 & High \\
\hline 3 & I respect the elderly and sympathize with the young. & 8 & 4.31 & 0.96 & High \\
\hline 4 & I practice justice when dealing with others. & 2 & 4.46 & 1.20 & High \\
\hline 5 & I tell the truth and don't give up that. & 9 & 4.26 & 0.97 & High \\
\hline 6 & I persist in meeting others pleasantly. & 21 & 3.78 & 1.29 & High \\
\hline 7 & I care for interacting with people and building new friendships. & 22 & 3.75 & 1.26 & High \\
\hline 8 & $\begin{array}{l}\text { I appreciate the value of equality between males and females in } \\
\text { treatment. }\end{array}$ & 16 & 4.02 & 0.99 & High \\
\hline 9 & I fight sectarianism and regionalism. & 11 & 4.22 & 1.09 & High \\
\hline 10 & I share people their happiness and sadness (social sharing). & 27 & 3.58 & 1.30 & High \\
\hline 11 & I accept other's opinions and discuss them subjectively. & 7 & 4.35 & 0.95 & High \\
\hline 12 & $\begin{array}{l}\text { I care for helping others when being exposed to something } \\
\text { wrong. }\end{array}$ & 4 & 4.42 & 0.99 & High \\
\hline 13 & I fight dealing with drugs in society. & 32 & 3.35 & 1.31 & Medium \\
\hline 14 & I work on standardized consumption. & 28 & 3.51 & 1.30 & High \\
\hline 15 & I fight nepotism. & 34 & 3.30 & 1.31 & Medium \\
\hline 16 & I respect the equality of opportunities. & 23 & 3.69 & 1.29 & High \\
\hline 17 & I face my own conditions with complete responsibility. & 18 & 3.97 & 0.97 & High \\
\hline 18 & $\begin{array}{l}\text { I commit to the laws, rules and regulations prevailing in the } \\
\text { society. }\end{array}$ & 17 & 3.96 & 0.97 & High \\
\hline 19 & I acknowledge favor to its owner. & 25 & 3.65 & 1.28 & High \\
\hline 20 & I execute the ethical promises, charters and commitments. & 30 & 3.39 & 1.31 & Medium \\
\hline 21 & I do my charges without depending on others. & 10 & 4.25 & 0.97 & High \\
\hline 22 & I forgive others and accept apologies. & 6 & 4.36 & 0.96 & High \\
\hline 23 & During emergencies, I behave firmly. & 33 & 3.34 & 1.26 & Medium \\
\hline 24 & I try to spread love among people. & 37 & 3.20 & 0.96 & Medium \\
\hline 25 & I share others in different things faithfully. & 36 & 3.24 & 0.88 & Medium \\
\hline 26 & I like collaborative work and team spirit. & 24 & 3.68 & 1.31 & High \\
\hline 27 & I try not to conceal the truth. & 20 & 3.85 & 1.17 & High \\
\hline 28 & I try to confirm my deeds to my words. & 5 & 4.39 & 1.00 & High \\
\hline 29 & I respect others' rights and properties. & 3 & 4.44 & 1.03 & High \\
\hline 30 & I try not to cheat or deceive in my work. & 12 & 4.18 & 0.92 & High \\
\hline 31 & I promote belonging and love of country. & 19 & 3.90 & 1.29 & High \\
\hline 32 & I solve problems logically. & 1 & 4.49 & 0.91 & High \\
\hline 33 & I do my duties accurately, honestly and faithfully. & 35 & 3.26 & 1.01 & Medium \\
\hline 34 & I keep environment clean, and I protect it. & 26 & 3.60 & 1.33 & High \\
\hline 35 & I appreciate deeds that deserve appreciation. & 13 & 4.15 & 1.26 & High \\
\hline 36 & I accept the work responsibilities sincerely and seriously. & 29 & 3.45 & 1.04 & Medium \\
\hline 37 & I believe in justice, equity and equality of opportunities. & 38 & 3.15 & 1.30 & Medium \\
\hline 38 & I listen to others politely and respectfully. & 31 & 3.38 & 1.26 & Medium \\
\hline \multicolumn{2}{|c|}{ The Entire Total } & 38 & 3.88 & 1.25 & High \\
\hline
\end{tabular}

* The maximum of students' answers (5) grades.

It an be noted from table 1 that the students' answers for the study items which were concerned with the practicing degree of social values among the Hashemite University B.A. students came in 2 levels, high and 
medium. Thus, the entire total of the questionnaire items was high, which means that the social values practiced by the B.A. students in light of the recent global changes were high in light of the students' answers on the study tool.

One of the items which have high degree means is the item (I solve problems logically) which occupied the first rank with a mean of (4.49), whereas the item (I practice justice when dealing with others) came second with a mean of (4.46). The item (I respect others' rights and properties) came third with a mean of (4.44). The item that took the $4^{\text {th }}$ rank was (I care for helping others when being exposed to something wrong) having a mean of 4.42). The $5^{\text {th }}$ rank was taken by the item (I try to conform my deeds to my words) which had a mean of (4.39). The item (I forgive others and accept apologies) came in the $6^{\text {th }}$ rank getting a mean of (4.36), whereas the item (I accept other's opinions and discuss them subjectively) took the $7^{\text {th }}$ rank with a mean of (4.35).

On the other hand, the following items came up with a medium degree of social values practice, in that the item (I accept the work responsibilities sincerely and seriously) occupied the $29^{\text {th }}$ position with a mean of (3.45), whereas the item (I execute the ethical promises, charters and commitments) came in the $30^{\text {th }}$ rank having a mean of (3.39). The $31^{\text {st }}$ rank was taken by the item (I listen to others politely and respectfully) which got a mean of (3.38). The item (I fight dealing with drugs in society) appeared in the $32^{\text {nd }}$ place with a mean of (3.35), and then comes the item (During emergencies, I behave firmly) in the $33^{\text {rd }}$ rank with a mean of (3.34). The $34^{\text {th }}$ rank was given to (I fight nepotism) which had a mean of (3.30). The item (I do my duties accurately, honestly and faithfully) came in the $35^{\text {th }}$ place with a mean of (3.26), followed by the item (I share others in different things faithfully) in the $36^{\text {th }}$ place with a mean of (3.24). Then came (I try to spread love among people) in the $37^{\text {th }}$ place with a mean of (3.20). The last place, $38^{\text {th }}$, was taken by the item (I believe in justice, equity and equality of opportunities) with a mean of (3.15).

When looking at the entire total for the questionnaire items, we can see that the mean was (3.88) and the standard deviation was (1.21) which indicates that there is a high degree of social values practicing among the B.A. degree students at the Hashemite University.

That result is considered justified since the items of the study tool touch the life of the university student in all aspects, either inside the university or outside it in family or society.

It can be indicated that since the current age is characterized with huge changes, it is essential to review the values and modify them or modify the conditions related to them. Also, the crisis this age is witnessing is a value crisis that resulted from the conflict between the old and the new values. Besides, there is an increasing awareness for the necessity of altering the old values and building a new world on the basis of new values. Thus, the value scale doesn't necessarily mean that it is still and not developing, indeed it is flexible changing as a result of experience and interaction between individuals and environment, and that agrees with what has been indicated by Al-Zyood (2004).

Since the focus of building personality exists in the values which are infiltrated within the individual, within his essence, his self and mind, and although these values reside in the deepness, yet they may be exposed to social change which is a necessity for all communities. The factors of influence and modification affect the society, both the inside and the outside, and it must respond to that change, whether its response is quick or slow which means that attitudes should be modified and values should be reviewed to take new values that were not common before, and that what has been indicated by (Malhas \& Subhi, 2002).

It can be noted from the students' answers on the questionnaire that the practicing degree of values for the entire total was high which means that the study sample participants were consistent to their social values they were raised on, considering the changes that occur as a result of globalization which affected different life aspects, and influenced the social values, especially the sample participants who are young and still imitating their parents' attitudes, and consequently the effect of globalization on them is still unclear.

$2^{\text {nd }}$ question: Are there statistically significant differences in the degree of social values practice among the B.A. students at the Hashemite University ascribed to the variables of (gender, students' studying level, place of living)?

One-Way ANOVA was used, and to answer this question, it was divided into 3 sub-questions as the following:

First: Are there statistically significant differences in the degree of social values practice among the B.A. students at the Hashemite University ascribed to the variable of gender?

To answer this question, one-way ANOVA was used as seen in table 2. 
Table 2. The degree of social values practice among students according to gender

\begin{tabular}{|c|c|c|c|c|c|c|c|}
\hline $\begin{array}{l}\text { Source } \\
\text { Variance }\end{array}$ & $\begin{array}{l}\text { Sum } \\
\text { Squares }\end{array}$ & of & $\begin{array}{l}\text { Degrees } \\
\text { Freedom }\end{array}$ & of & Mean of Squares & F - value & $\begin{array}{l}\text { Statistical } \\
\text { significance }\end{array}$ \\
\hline Between groups & 146.25 & & 1 & & 146.25 & & \\
\hline Inside groups & 35966.25 & & 948 & & & & \\
\hline Total & 36112.83 & & 950 & & 32.73 & 4.47 & $* 0.032$ \\
\hline
\end{tabular}

* statistically significant at the level of $(\boldsymbol{\alpha} \leq \mathbf{0 . 0 5})$

As can be seen in Table 2, there are statistically significant differences ascribed to the variable of gender for the practicing degree of social values among the Hashemite University students, and for the benefit of female students.

This result can be explained that the female students usually face the society's restraints on their roles, activities and movements. Also, the Jordanian society is a masculine one that offers males a sense of transgression, and on the other side it treats females strictly. Thus, we found that females' are more committed to social values than males. Males usually have more freedom for choosing any available job, whereas females have got limited fields although currently there are many attempts to enroll females in all job fields while preserving the inherited values. But these attempts face a strong resistance from the masculine society, particularly the traditionalists, but that doesn't mean abandoning the inherited values, yet it means that they should take into account the age's requirements.

The result of this study agrees with the result of Alayyan's \& Aseileh's study (2004) which indicated that there are differences in the practiced social values for the benefit of female students, but it contradicts with the result of Al-Hadidi's study (2000) which indicated the existence of differences in the extent of students' commitment to values for the benefit of male students. It also contradicts with Abu-Zaid's \& Al-Zyood's study (2007) whose results showed that there were no differences in the interest in values ascribed to the variable of gender.

Second: Are there statistically significant differences in the degree of social values practice among the B.A. students at the Hashemite University ascribed to the variable of students' studying level?

To answer this question, one-way ANOVA was used as seen in Table 3.

Table 3. The degree of social values practice among students according to students' studying level

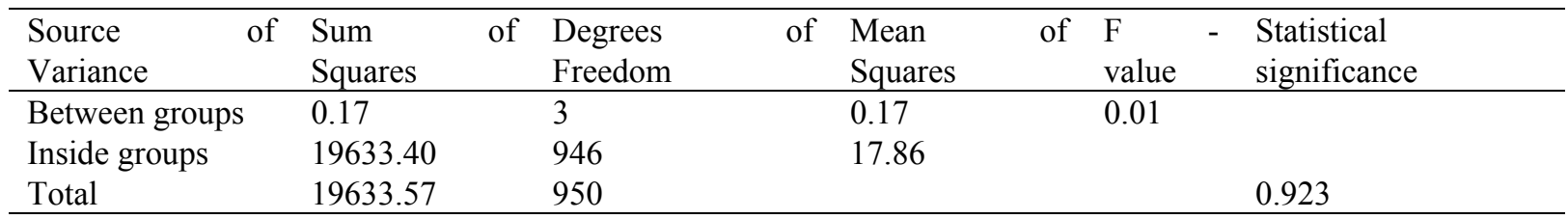

As can be seen in Table 3, there are no statistically significant differences ascribed to the variable of studying level for the practicing degree of social values among the Hashemite University students, which means that there is no difference in the practicing degree of social values ascribed to the students' studying level.

This result can be explained that the students within the study sample, regardless of their studying level, are attached to their original social values which reflect their commitment to the inherited values without being affected by the modern values that might have negative and unacceptable effects in the society where the student lives, whether in his family or with his classmates, so he would be criticized by them. Also, students at this age, although they seek self-realization, they also seek to be obedient to their families through being attached to original habits and traditions away from mobs or social rebellion. This result disagrees with the result of Freihat's study (1998) which indicated no existence of an influence of students' studying level on the belief level of values system.

Third: Are there statistically significant differences in the degree of social values practice among the B.A. students at the Hashemite University ascribed to the variable of place of living?

To answer this question, one-way ANOVA was used as seen in Table 4. 
Table 4. The degree of social values practice among students according to place of living

\begin{tabular}{|c|c|c|c|c|c|c|c|c|}
\hline $\begin{array}{l}\text { Source } \\
\text { Variance }\end{array}$ & $\begin{array}{l}\text { Sum } \\
\text { Squares }\end{array}$ & of & $\begin{array}{l}\text { Degrees } \\
\text { Freedom }\end{array}$ & of & $\begin{array}{l}\text { Mean } \\
\text { Squares }\end{array}$ & of & $\begin{array}{l}\mathrm{F} \\
\text { value }\end{array}$ & $\begin{array}{l}\text { Statistical } \\
\text { significance }\end{array}$ \\
\hline Between groups & 73.31 & & 2 & & 73.31 & & & \\
\hline Inside groups & 20020.25 & & 947 & & 18.22 & & & \\
\hline Total & 20093.56 & & 950 & & & & 4.02 & $* 0.045$ \\
\hline
\end{tabular}

* statistically significant at the level of $(\boldsymbol{\alpha} \leq \mathbf{0 . 0 5})$

As can be seen in Table 4, there are statistically significant differences ascribed to the variable of place of living for the practicing degree of social values among the Hashemite University students.

To discover the source of differences within the variable if place of living, (L.S.D) test was used as illustrated in Table 5 .

Table 5. Results of (L.S.D) test according to place of living

\begin{tabular}{lll}
\hline $\begin{array}{l}\text { Students' place of } \\
\text { living }\end{array}$ & $\begin{array}{l}\text { Camps' } \\
\text { residents }\end{array}$ & $\begin{array}{l}\text { Rural areas' residents } \\
\text { Camps' residents }\end{array}$ \\
$\begin{array}{l}\text { Rural areas' residents } \\
\text { City residents }\end{array}$ & $* 23.18$ for the benefit of rural residents & $\begin{array}{l}6.18 \\
* 26.34 \text { for the benefit of rural } \\
\text { residents }\end{array}$ \\
\hline
\end{tabular}

* statistically significant at the level of $(\boldsymbol{\alpha} \leq \mathbf{0 . 0 5})$

Results displayed in Table 5 that are related to (L.S.D) test results for comparing between the means of practicing degree of social values according to the variable of place of living show that there are statistically significant differences between students living in camps and rural areas, and for the benefit of rural areas residents. They also show that there are statistically significant differences between the students living in rural areas and the city, for the benefit of rural areas residents. That means the level of practiced social values among the Hashemite University students, based on the students' answers on the study tool, was for the students living in rural areas.

Such a result is considered a reflection for the rural families' commitment to habits and traditions which in turn affects their children's behavior who are committed to these practiced social values. These values are manifested in loving people, sympathizing with them, as well as being connected to our daily deeds in their character which make them either fair or unfair, correct or incorrect, and the judgments they issue have got a definite effect. But people differ in these judgments, and the social values assert respecting the family, considering it the nuclear of social structure. They also assert social solidarity, social care, rejecting selfishness and individualism, preferring chivalry, forgiveness when being able, as well as social work for not exploiting man and sanctifying work, and others. Besides, the existence of differences for the benefit of students living in rural areas doesn't mean that other students are not committed to social values, but the practice image was clearer and more evident among the students who live in the countryside than other students.

This result is compatible with the finding of Al-Ostath's \& Hamdan's study (2004) which indicated the existence of differences for the benefit of the variable of place of living.

\section{Recommendations}

- $\quad$ Reinforcing the social values among the Hashemite University students so as to obtain a higher degree of importance through holding educational workshops and seminars for students that would deepen their understanding and respect for the social values.

- Continuing the enhancement of social values available among students through the instructional curricula.

- Conducting a study around the impact of current global new conditions on the social values practiced by the students of other Jordanian universities. 


\section{References}

Abdullah, A. A. (1999). Globalization: Its roots, branches and how to deal with. Alem Alfikr Journal, 28(2).

Abu-Zaid, M., \& Al-Zyood, M. (2007). The Educational Values among the Secondary Stage Students in Amman as They see them themselves. Dirasat Journal, 34, 735-766.

Al-Amr, M. (2001). Current Social Issues (1st ed.). Dar Alkitab Aljame'y, AlEin, UAE.

Alayyan, M., \& Aseileh, E. (2004). Trends towards modernity and its relation to the system of values for the current university youth for Al-Aqsa revolution. The $1^{\text {st }}$ conference for the college of education, Islamic University, Ghaza, Palestine.

Al-Bahi, F. (1985), Social Psychology. Dar Al-Fikr Al-Arabi, Cairo.

Al-Hneity, M. (2003). Conflict between social values and organizing values among the Jordanian government sector employees, a field study. Dirasat Journal, 30(2), 398-414.

Al-keelani, M. E. (1988). The Islamic Education Philosophy (2nd ed.). Makkah. Hadi Library, Saudi Arabia.

Al-Ostath, M., \& Muhammad, H. (2004). Evaluating the University's Role as a System in Building the Young's Personality from A Value Perspective. A research presented to the $2^{\text {nd }}$ annual conference in Zarqa Private University " University Youth: His Culture \& Values within a changing world", held between 27-29, July, 2004, Jordan.

Al-Tall, A. (1998). Higher Education in Jordan. Jordan History Publications, the Royal Assembly for Islamic Civilization Researches, Amman.

Al-Zyood, M. (2004). The Value Conflict among Jordanian University Students in light of the Current Global changes, and their perspectives of the university environment's contribution to it. Unpublished Ph.D. dissertation, Arab Amman University for Higher Education, Amman, Jordan.

Aqeel, H., \& Ezz, A. A. A. (2001). The value classification for globalization. The publications of ELGA, Malta.

Dhiab, F. (1980). Values \& social habits. Beirut: Dar Al-Nahda for printing and publishing.

Freihat, H. (1998). The Current Value System Among the female students at the Jordanian universities. Unpublished M.A. dissertation, Yarmouk University, Jordan.

Hijazi, A. (1999). Globalization \& Margining the National Culture, A criticizing vision from the 3rd world, Journal of Alem Al-Fikr, 28(2).

Ja'neini, N. (2004). Philosophy and its Educational Applications (1st ed.). Amman, Wa'el Press for publishing \& distribution.

Khaleifeh, A. A. (2004). Change in values system among the university youth: Aspects \& Causes. A research presented to the 2nd annual conference in Zarqa Private University "University Youth: His Culture \& Values within a changing world", 27-29, July, 2004, Jordan.

Malhas, D., \& Tayseer, S. (2002). A Comparative Study between the cognitive, social, cultural, scientific, and ethical values for the students of Al-AlBayt and Jordan Universities. Journal of Educational Researches Centre, 21(11), 55.

Oweidat, A. (1991). The value trends among the University of Jordan students. Dirasat Journal, 18(3), $205-239$.

Shoman, M. (2001). The Role of the Arabian Family in the field of Social Raising-up in light of globalization. Retrieved from http//:iplog4.sahaf.net.Sa/2001/jaz/feb/2/ar

Shukri, F. (2002). The Ethical values between Philosophy and Science. knowledge press, Egypt.

Zaqoot, H. (2000). Heading towards modernization among Ghaza Islamic University female students in light of some current values. M.A. dissertation, College of Education, Islamic University, Ghaza, Palestine.

Zarqa Private University. (2004). University Youth: His Culture \& Values within a changing world. The 2nd annual conference of Zarqa Private University, Zarqa, Jordan.

\section{Copyrights}

Copyright for this article is retained by the author(s), with first publication rights granted to the journal.

This is an open-access article distributed under the terms and conditions of the Creative Commons Attribution license (http://creativecommons.org/licenses/by/3.0/). 